\title{
Smart management and irrigation demand monitoring in Cyprus, using remote sensing and water resources simulation and optimization
}

\author{
G. Papadavid ${ }^{1}$, D. Hadjimitsis ${ }^{2}$, K. Fedra ${ }^{3}$, and S. Michaelides ${ }^{4}$ \\ ${ }^{1}$ Cyprus University of Technology, Lemesos, Cyprus \\ ${ }^{2}$ Agricultural Research Institute of Cyprus, Nicosia, Cyprus \\ ${ }^{3}$ Environmental Software \& Services GmbH, Austria \\ ${ }^{4}$ Meteorological Service, Nicosia, Cyprus
}

Received: 13 September 2010 - Revised: 16 February 2011 - Accepted: 10 March 2011 - Published: 9 May 2011

\begin{abstract}
This paper presents a research project which integrates technological tools for developing a complete system for monitoring and determining irrigation demand on a systematic basis in Cyprus. Such tools are multi-spectral remotely sensed data dynamic water budget simulation and optimization, crop evapotranspiration (ETc) models and microsensor technology. The main aim is to estimate ETc in Cyprus and, furthermore, to undertake the required measures for an effective irrigation water management in the future. Evapotranspiration is difficult to determine since it combines various meteorological and field parameters while in literature quite many different models for estimating ETc are put forward. The proposed wireless sensor network acts as a monitoring tool for providing measurements of the necessary parameters: meteorological, climatic data and other auxiliary parameters required by the irrigation model in order to determine the irrigation demand.

Reflectance is determined directly from satellite images. Finally, using the WaterWare irrigation software, irrigation scheduling is planned for the area of interest in Paphos, Cyprus. This area is located at almost sea level and is characterized by mild micro-climate. The results of the paper refer to year 2009 and show the daily water requirements of the specific crop in study.
\end{abstract}

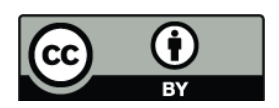

Correspondence to: D. Hadjimitsis (d.hadjimitsis@cut.ac.cy)

\section{Introduction}

The agricultural sector is one of the major consumers of water, consuming more than $70 \%$ of the world's fresh diverted water use from rivers and groundwater. Thus, the use of irrigation water plays a significant part in increasing land productivity (Ahmad et al., 2008; Hongjun et al., 2008). One of the main components of the water balance is the water loss via evapotranspiration, which is proportional - among others - to the vegetation cover of a region. Remote sensing is a very useful research tool in identifying irrigated areas and classify vegetation coverage. The objective of this research project is to describe and apply a procedure for monitoring and improving the performance of on-demand irrigation networks, based on the integration of remote sensing techniques and simulation modelling of irrigation water in Cyprus. The country is facing a severe drought in the last five years. Multi-spectral satellite images are used to infer crop potential evapotranspiration which is the main input for water balance simulations.

Evapotranspiration (ET) is referred to as the combination of two different processes: in the first, water is lost from the soil and plant surfaces by evaporation and in the second, by the crop's transpiration (FAO., 1998). The actual estimation and calculation of evapotranspiration is needed for climate studies, weather forecasts, hydrological surveys, ecological monitoring, and water resource management (Hoedjes et al., 2008). Evapotranspiration constitutes a main component of the hydrological cycle and its estimation requires auxiliary hydro-meteorological data. Many formulas have been developed in order to calculate evapotranspiration. 
The need for estimating ETc in Cyprus, is essential in order to determine the exact quantity of irrigated water needed for specific crops (Hadjimitsis et al., 2008). Excessive use of water and, in particular, use of groundwater for irrigation, is not sustainable. The determination of ETc for irrigation purposes can be used as a vital tool for supporting the decision making process in the management of water resources of Cyprus. Irrigation water requirements not only constitute the quantitatively largest components of overall water demands, but they also show an "unfavourable" timing, coinciding with the dry summer period and the tourist season which leads to peak water demands. At the same time, considering water as an economic good (Dublin principle No. 4), the economic efficiency of irrigated agriculture on Cyprus is comparatively low compared to alternative water uses. Socio-political considerations dominate the allocation patterns (Klohn, 2002). The objective of IWRM (Integrated Water Resources Management, as mandated in the Water Framework Directive 2000/60/EC) is to find and implement sustainable consumption and allocation patterns that, not only meet hydrological constraints, but also contribute to socio-economic and environmental objectives. To balance these considerations in a physically sound water budget and allocation model requires a multi-criteria approach. The intended purpose of this paper is to estimate actual crop evapotranspiration in Cyprus for specific crops by integrating technological tools for developing a complete system for monitoring and determining irrigation demand. The target is to manage a systematic tool by taking advantage of remote sensing technology in order to control and monitor irrigation management.

In the past decades, the estimation of evapotranspiration combining conventional meteorological ground measurements with remotely-sensed data has been widely studied and several methods have been developed for this purpose. Reference evapotranspiration values, can be calculated by measuring weather conditions and typical reference crops using specialized instruments, such as the lysimeters. Currently, it is recognized that estimating evapotranspiration can be performed quite accurately by using appropriate relationships and remotely sensed data. Weather data (e.g., solar radiation, air temperature, relative humidity and wind run) can also be used in these estimations using remotely sensed data. Data from different satellite sensors are also useful in providing information at various temporal and spatial scales (e.g., NOAA (National Oceanic and Atmospheric Administration, see Gieske and Wouter, 2005), Landsat TM/ETM+ (see Hafeez et al., 2002; Sobrino et al., 2004; Stathopoulou et al., 2007; Qin and Karnieli, 2001), ASTER (Advanced Spaceborne Thermal Emission and Reflection, see French et al., 2001). Remote sensing has several advantages compared to field measurements, since remote sensing data cover a large area and information can be spatially represented in maps through Geographic Information Systems (G.I.S.), revealing spatial characteristics that are often not apparent when such information is provided in other forms, such as tables or text (Bastiaanssen and Bos, 1999). Different methods and models have been developed in order to use this information from remote sensing in surface flux estimation schemes. It is difficult to classify all of these methods due to their complexity; these models are based either on empirical or physically methods. Nevertheless, three main and general categories can be identified: (a) empirical direct methods, (b) residual methods and (c) indirect methods. (see Courault et al., 2005).

\section{Resources and methodology}

\subsection{Case study}

The Paphos district has been selected for this case study. The irrigation supply of Paphos area is provided by the following: Asprokremmos Dam reservoir, 24 boreholes drilled in the gravel aquifers of the major river beds Dhiarizos, Xeropotamos and Ezousas rivers and the coastal calcarenite aquifer. The irrigated area near the Asprokremmos dam is used as a pilot study area in this project. The study area is located in the area of Mandria village, in the vicinity of Paphos International Airport (Fig. 1). The area lies at almnost sea level and is characterized by a mild climate which favors early production of leafy and annual crops. The uniform and moderate temperatures, attributed to the proximity of the sea, along with the high humidity, are conductive to early production of fruit and vegetables. Cereals are also grown in the area. A typical Mediterranean climate prevails, with hot dry summers, from June to September, and cool winters, from December to March, during which much of the annual rainfall occurs (annual average is $425 \mathrm{~mm}$ ). Nevertheless, irrigation is indispensable for any appreciable agricultural development in the area. Morphologically, the area is a flat terrain of about $30 \mathrm{~km}^{2}$. The soil dominant in the area is the Cambisol type (calcic and chromic types). Cambisol is soil with a beginning of soil formation with weak horizon differentiation and mostly brownish discoloration or structure formation in the soil profile. Most of these soils make good agricultural land and are intensively used. Cambisols in temperate climates are among the most productive soils on earth. The soil texture is loamy to clayey. Signs of beginning clay illuviation may be detectable in the cambic horizon but the clay content is normally highest in the A-horizon. The soil of the experimental site is calcareous, characterized by a deep brown color, and having a rather heavy to very heavy structure.

\subsection{Resources}

For estimating evapotranspiration using FAO PenmanMonteith method, auxiliary meteorological data were used. Air temperature, atmospheric pressure, wind velocity and other data were collected from an automatic weather station, located near the study area (Fig. 2). The necessary meteorological data form the basis for validating the data collected 

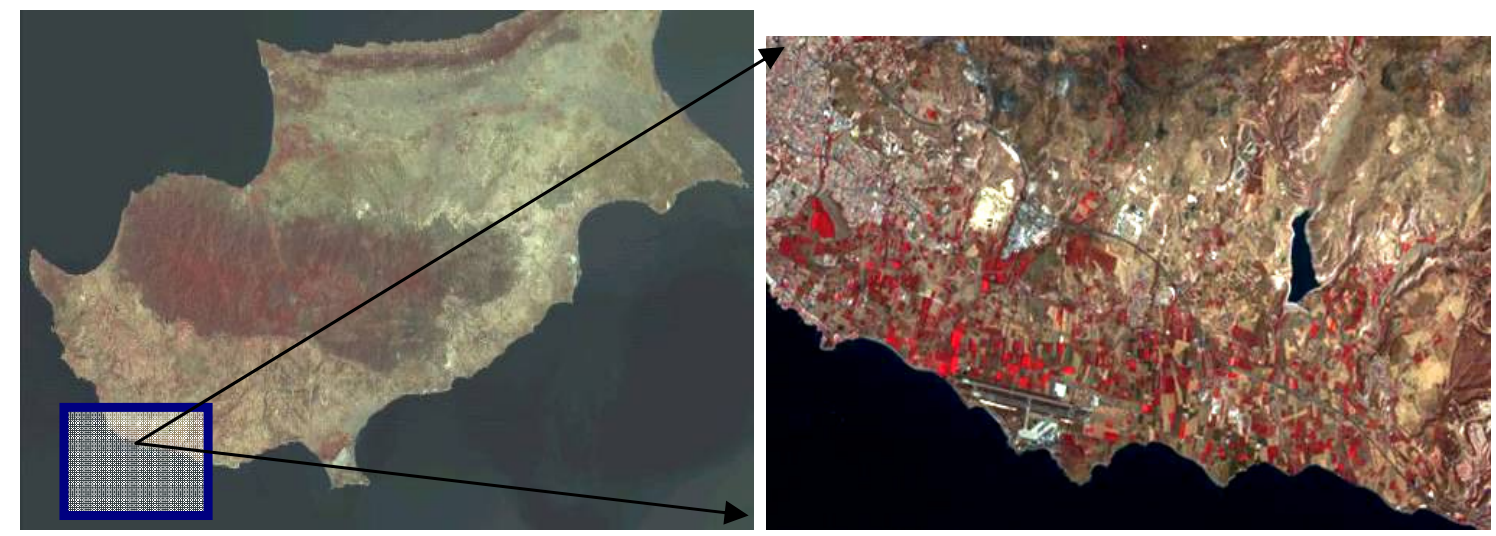

Fig. 1. Selected case study $\left(456182,3840861\right.$, WGS 84 , UTM $36^{\circ}$ N).

from the wireless sensors network which was installed in the field of interest.

Multi-spectral, ASTER and Landsat 7 ETM+ satellite images, for the past two years have being used in this research. For the pre-processing and processing of the satellite images, the ERDAS IMAGINE software was used. In situ sunphotometer and spectro-radiometer measurements were also taken. These measurements are used to validate the satellite data after removing atmospheric and radiometric effects on the images (Papadavid et al., 2009).

More specifically, a five-channel handheld Microtops II sun-photometer (Solar Light Co., http://www.solar.com/) operated from 380 to $1020 \mathrm{~nm}$ is used. The sun-photometer is used to derive the AOT (Atmospheric Optical Thickness) and the water vapour concentrations during the satellite overpass, so as to assist the effective removal of atmospheric effects. The GER1500 field spectro-radiometer was also used in this research project (http://www.spectravista.com). The GER1500 field spectro-radiometer is light-weight with high performance spectral reflectance's accuracy, covering the ultraviolet, visible and near-infrared wavelengths from $350 \mathrm{~nm}$ to $1050 \mathrm{~nm}$. GER 1500 uses a diffraction grading with a silicon diode array which has 512 discrete detectors and provides the capability to read 512 spectral bands. The instrument possesses a rapid scanning rate, acquiring spectra in milliseconds. The spectro-radiometer is used to derive the spectral reflectance values of various crops in the selected agricultural fields and to support the derivation of reflectance values from medium and high resolution images.

For the Paphos irrigation district, the model includes the hydrological catchment of the Asprokremmos dam, the dam itself and its reservoir (with a design inflow of 45.5 million $\mathrm{m}^{3}$, of which only about $15 \mathrm{Mm}^{3}$ have been recorded in the period of 1971-2000). The dam supplies two major consumers: the irrigation district of a total of 5000 ha (dominated by open field vegetables but also bananas, grapes and tobacco) and the city of Paphos and suburbs ( 70000 inhabitants with an average daily water demand of $2201 /$ capita,

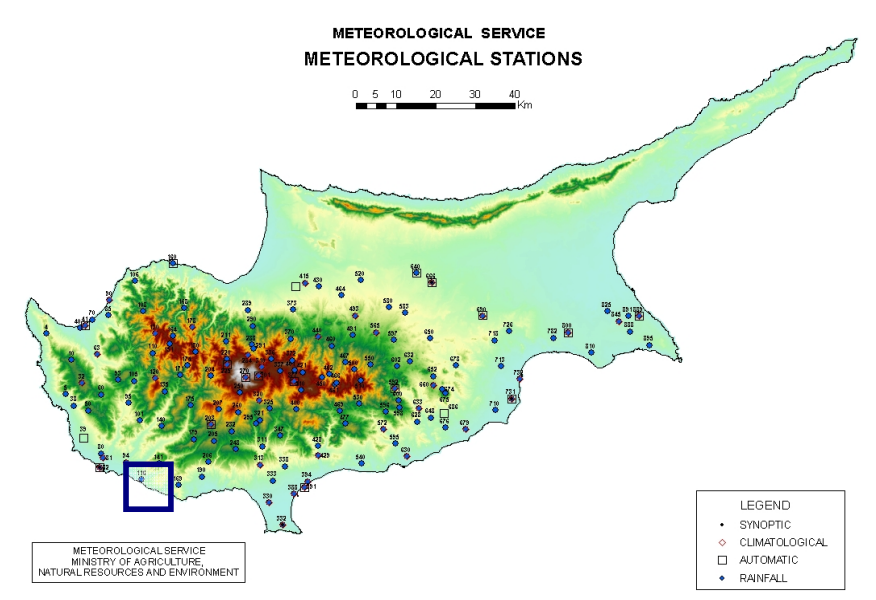

Fig. 2. Map showing the meteorological stations in Cyprus.

which amounts to about $6 \mathrm{Mm}^{3}$, with an additional 3-4 $\mathrm{Mm}^{3}$ for the tourist industry). Additional water supply for the irrigation is available from 24 well fields from 4 distinct local aquifers of neighbouring basins; a desalination plant which is planned to provide for domestic water use and coastal tourism, with a design capacity of $200001 /$ day, is under construction.

\subsection{Methodology}

The three-step methodology of the paper is described in the following (see also Fig. 3):

1. Pre-processing and processing of the satellite images, include geometric correction (second order polynomial transformation), geo-reference of the image using ground control points (WGS 84/UTM/Zone 36 North), radiometric correction in order to obtain the same comparable units for each image, and finally atmospheric correction by employing the darkest pixel method (histogram minimum method) in order to get the true 


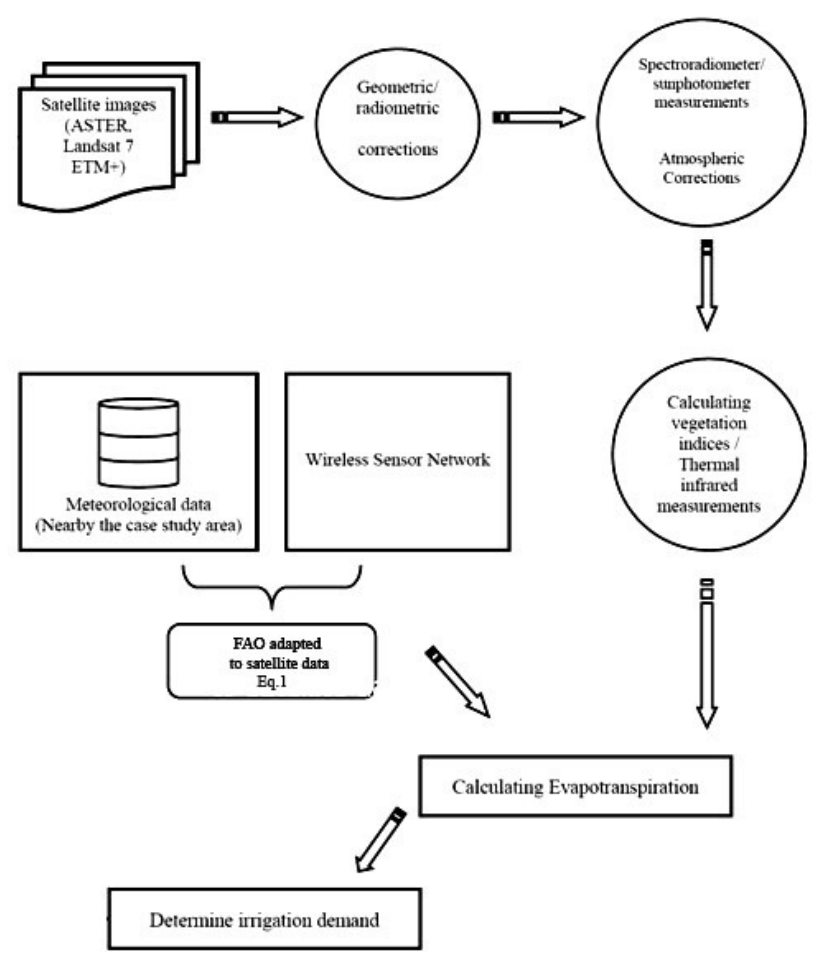

Fig. 3. Methodology diagram.

reflectance of each pixel of the image (Hadjimitsis et al., 2004; Hadjimitsis et al., 2008). Finally, Liang's equation (Liang, 2000) for deriving albedo was employed in this research for ASTER images. For Landsat images, weighted coefficients and irradiance were used for calculating albedo for each image (Zoran and Stefan., 2006).

2. In order to estimate ETc, the one step FAO PenmanMonteith adapted to satellite data method was applied. The specific equation (Eq. 1, below) which has been used in European Projects such as DEMETER (http: //www.demeter-ec.net/) and PLEIADES (http://www. pleiades.es) to estimate ETc under assumptions, relies on the direct application of the Penman-Monteith equation with canopy parameters estimated from satellite imagery. For estimating evapotranspiration, meteorological and satellite data have been used. Air temperature, atmospheric pressure, wind speed and other data were collected through a wireless sensor network which is employed in the fields of the study area. Satellite data, such as LAI (Leaf Area Index) and albedo maps, have been derived from satellite imagery using simplified methods (D’Urso et al., 1995).

$$
\begin{aligned}
& \mathrm{ETc}= \\
& \frac{86400}{\lambda}\left[\frac{s\left(1-0.4 e^{-0.5 \mathrm{LAI}}\right)(1-a)(\mathrm{K} \downarrow+L *)+c_{p} p_{a}\left(e_{s}-e_{a}\right) U / 124}{s+\gamma(1+U / 0.62 \mathrm{LAI})}\right]
\end{aligned}
$$

Adv. Geosci., 30, 31-37, 2011
Where, ETc is the crop evapotranspiration $\left(\mathrm{mm} \mathrm{day}^{-1}\right)$, $\mathrm{K} \downarrow$ is the incoming solar radiation $\left(\mathrm{MJ} \mathrm{m}^{-2} \mathrm{day}^{-1}\right.$ ) and $U$ the wind speed $\left(\mathrm{m} \mathrm{s}^{-1}\right)$; the other variables, namely $L^{*}$ (net longwave radiation in $\mathrm{MJ} \mathrm{m}^{-2} \mathrm{day}^{-1}$ ), cp (air specific heat in $\mathrm{J} / \mathrm{kg} / \mathrm{K}$ ), $\rho$ a (air density in $\mathrm{kg} / \mathrm{m}^{3}$ ), $\mathrm{e}_{s}$ the saturation vapour pressure $(\mathrm{kPa}), \mathrm{e}_{a}$ is the actual vapour pressure (kPa), (es-ea) (vapour pressure deficit in $\mathrm{kPa}$ ), $\lambda$ (latent heat of vaporisation of water) and $\gamma$ (thermodynamic psychrometric constant in $\mathrm{kPa}^{\circ} \mathrm{C}^{-1}$ ) are calculated from air temperature and humidity at $2.0 \mathrm{~m}$ reference height. LAI is the ratio of the total area of all leaves on a plant to the ground area represented by the plant. It is an indicator of biomass and canopy resistance in $\left(\mathrm{m}^{2} / \mathrm{m}^{2}\right)$. This equation is valid under conditions of high solar irradiance (typical summer condition in Mediterranean climate) and for $\mathrm{LAI}>0.5$, which is the case of Cyprus. The height of the crops was defined from direct observations.

3. WaterWare (Harmancioglu et al., 2008; Fedra et al., 2007) is a dynamic water budget model that supports multi-criteria optimization of water allocation and use. The model system uses a topological network structure to represent water resources systems (river basins including inter-basin transfers); cascading submodels describe the dynamic mass budget in terms of hydro-meteorology, rainfall-runoff modelling for subcatchments, reservoir operations, irrigation water demand, and water quality. Economic valuation of water use and the costs of water supply include social and environmental criteria.

A core component of the dynamic water budget is the irrigation water demand estimation models, that simulates supplementary irrigation water demand based on predicted or observed meteorology, crops and cropping patterns, individual crop physiological water demand and resulting evapotranspiration estimates, and the irrigation strategies, expressed as a temporal sequence of soil moisture requirements. The evapotranspiration measurements from the remote sensing methodology are used to calibrate and validate the irrigation model component. The optimization considers the different costs (and capacity constraints) of these water sources, the possibility to modify irrigated area, crops, and cropping patterns (with very limited possibility to further improve irrigation efficiency), reduction of conveyance and distribution losses (the Paphos urban network has a reported 30\% loss rate).

Criteria for the optimization include the overall and sectorial supply/demand ratio, reliability of supply and a number of cost/benefit parameters including the valuation of social considerations (employment, farm income) and environmental water supply, and criteria of sustainability (groundwater exploitation). The optimization method uses the full resolution dynamic and 


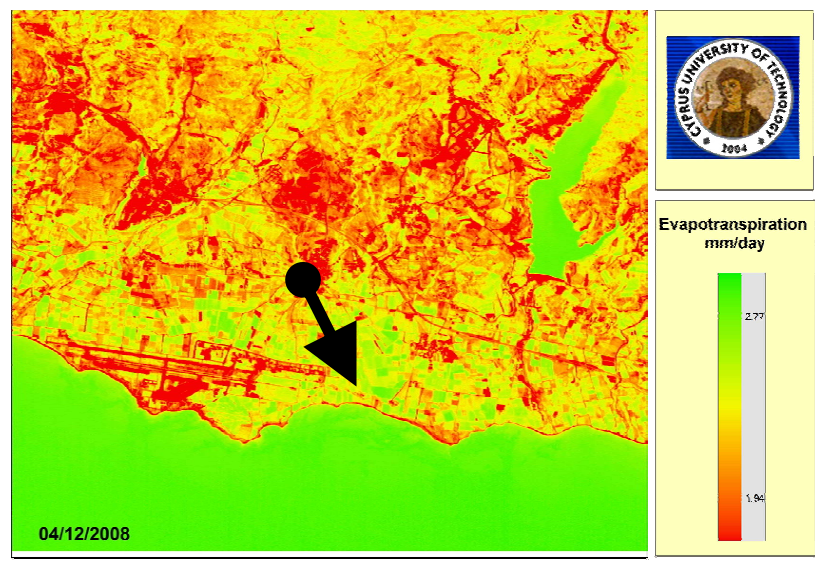

Fig. 4. Map showing the ETc as calculated for ASTER images using GIS software.

non-linear model system over a water year and vegetation period with a daily time step. It combines a first phase based on a set of stakeholder defined constraints for any and all of the criteria, using a combination of adaptive heuristics and genetic algorithms to efficiently generate feasible solutions. This is followed by a second phase of discrete multi-criteria selection using a reference point methodology to define an efficient compromise solution that maximizes overall shareable net benefits as the basis for win-win strategies.

\section{Results}

\subsection{Evapotranspiration monitoring and estimation}

The FAO Penman-Monteith method has been applied and the results are shown in Table 1. Atmospheric correction has been found to be very critical for estimating Etc. Approximately, an error of 5\% less than the calculated "ETc" mean, was recorded due to atmospheric effects. Figure 4 shows a representation of evapotranspiration on a satellite image for the area of interest.

The results are acceptable since, as it is indicated, ETc is increasing as we move towards spring and summer time, which is reasonable due to higher incoming solar radiation. The first two images show similar results since they have a time-difference of one week. The difference was calculated less than $0.01 \mathrm{~mm} /$ day and moreover no significant variations of evapotranspiration have been observed. Furthermore the results indicate that ETc of the early irrigated vegetables which are cultivated in the area, variable from 2.22 to 2.27 in February, and a slightly decrease of evapotranspiration was recorded. During the summer season of 2008, where leafy vegetables are cultivated, an increase of $20 \%$ of evapotranspiration was recorded, compared to ETc during winter season. As expected, the highest evapotranspiration mean measurement was recorded during summer time. Finally a decrease of the reference evapotranspiration can be seen $(2.65 \mathrm{~mm} /$ day $)$.

\subsection{Application of WaterWare}

Within the framework of determining optimum allocation of water in the case study area, an irrigation water demand model was run as part of WaterWare. The estimated ETc $(\mathrm{mm} /$ day, based primarily on AlfaAlfa) is summarized in Table 2. WaterWare estimates ETc based on "optimum" soil moisture maintained by supplementary irrigation during the growing season. Estimates represent the daily average rather than an instantaneous value that will also vary considerably during the day. ETc also varies from day to day, based on the meteorological conditions.

The resulting water demand for the irrigation areas is then used in a dynamic water budget model of the overall basin, reservoir and groundwater, which allocates the water to different competing water uses, considering hydrological, economic, and environmental criteria and objectives, as well as an alternative water supply from desalination to maximize overall net benefits as the basis for more efficient and cooperative win-win strategies of water allocation that not only improve the economic performance, but also meet sustainability criteria (Fig. 5). The difference in Etc, in $\mathrm{mm} /$ day, sourcing from two different methods (Penman-Monteith adapted to satellite data and WaterWare) may seem to be insignificant but it could be crucial when it comes to irrigation scheduling with stressed water resources. Of course, both techniques have a sound base: WaterWare is based on a hydrological model and remote sensing is based on energy balance and uses energy fluxes to estimate ET. The differences are in logical margins, since the method for estimating ET is different for each technique.

\section{Conclusions}

The goal of this paper was to create a platform using two modern tools, namely, remote sensing and modelling. The results have shown that both methods could be used for estimating ETc. The idea was to find a systematic tool for monitoring irrigation demand over Cyprus. These promising results illustrate how remote sensing data combined with the WaterWare model can be used in order to estimate evapotranspiration and hence monitor irrigation demand. The integration of modelling and remote sensing can provide accurate results on a systematic basis in order to develop irrigation management and provide scientific data to policy makers. The application of the integration was demonstrated in a pilot study. Future work will include further validation of the results, not only by applying the Penman-Monteith method for other crops, but also by adopting other acceptable methods and models for estimating evapotranspiration. 


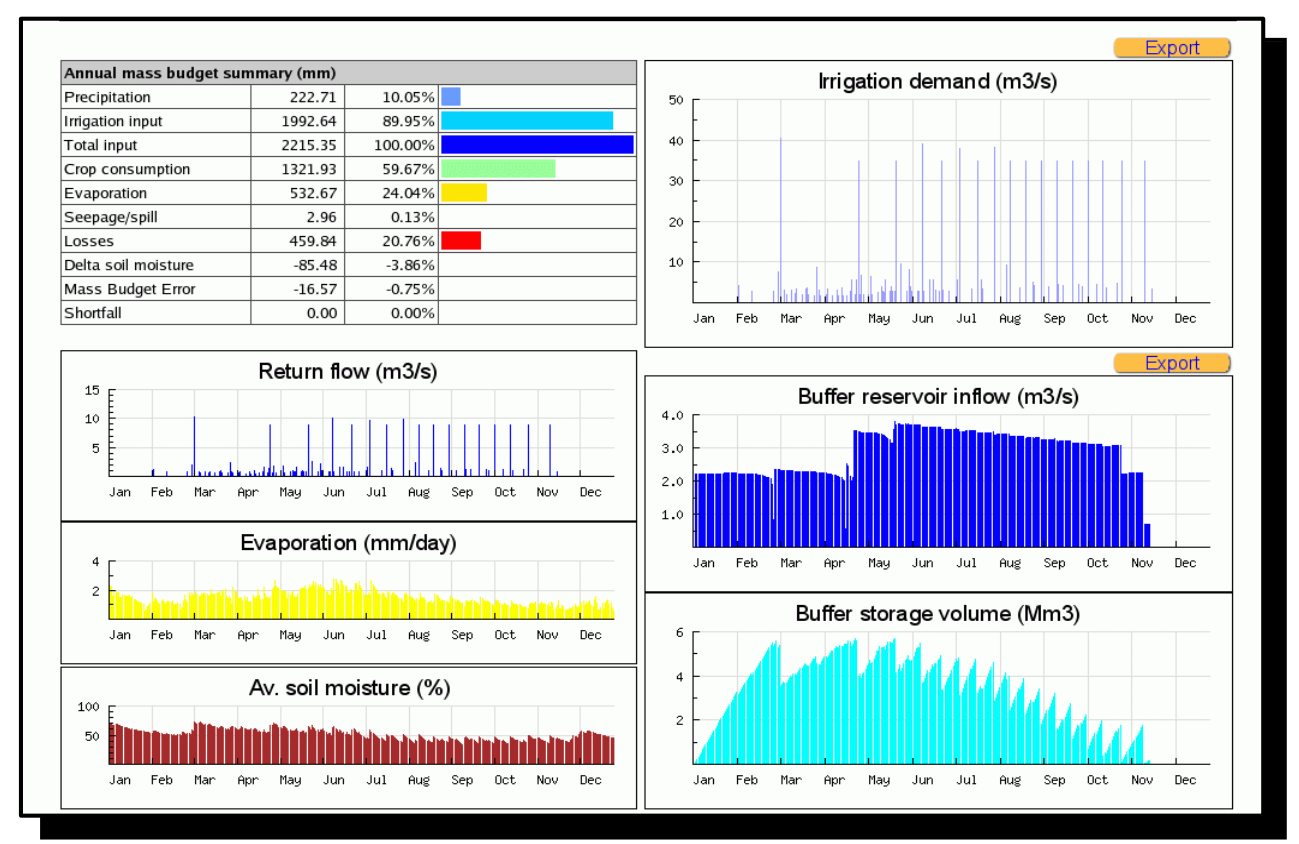

Fig. 5. Projection of WaterWare model in estimating Etc.

Table 1. Results of the FAO Penman-Monteith method for estimating ETc $(\mathrm{mm} / \mathrm{d})$.

\begin{tabular}{lllccc}
\hline No & Date of Satellite image & Satellite & ETc mean & ETc max & ETc min \\
\hline 1 & 17 December 2007 & ASTER & 2.33 & 2.36 & 2.29 \\
2 & 24 December 2007 & ASTER & 2.34 & 2.38 & 2.27 \\
3 & 26 February 2008 & ASTER & 2.25 & 2.27 & 2.22 \\
4 & 28 July 2008 & LANDSAT 7 ETM+ & 2.78 & 2.85 & 2.74 \\
5 & 13 August 2008 & LANDSAT 7 ETM+ & 2.84 & 2.88 & 2.77 \\
6 & 29 August 2008 & LANDSAT 7 ETM+ & 3.03 & 3.07 & 2.99 \\
7 & 4 December 2008 & ASTER & 2.65 & 2.69 & 2.60 \\
\hline
\end{tabular}

Table 2. FAO Penman Monteith versus WaterWare ETc estimates $(\mathrm{mm} /$ day $)$.

\begin{tabular}{lcc}
\hline Observation Date & ETc (FAO P-M) & ETc (WaterWare) \\
\hline 26 February 2008 & 2.25 & 2.20 \\
28 July 2008 & 2.78 & 3.20 \\
13 August 2008 & 2.84 & 3.20 \\
29 August 2008 & 3.03 & 2.40 \\
4 December 2008 & 2.65 & 2.70 \\
\hline
\end{tabular}

Acknowledgements. The authors would like to express their appreciation to Cyprus Research Promotion Foundation (www.research.org.cy) and the Cyprus University of Technology for their funding support. Thanks are given to the Remote Sensing Laboratory of the Department of Civil Engineering \& Geomatics at the Cyprus University of Technology (www.cut.ac.cy). Also, the authors are thankful to the Meteorological Service of Cyprus for the meteorological measurements which were kindly provided for the needs of this paper.

Edited by: S. Athanasatos

Reviewed by: two anonymous referees 


\section{References}

Ahmad, M. D., Turral, H., and Nazeer, A.: Diagnosing irrigation performance and water productivity through satellite remote sensing and secondary data in a large irrigation system of Pakistan, Agr. Water Manag. 96, 551-564, 2008.

Bastiaanssen, W. G. M. and Bos, M. G.: Irrigation performance indicators based on remotely sensed data: a review of literature, Irrig. Drain. Syst., 13, 291-311, 1999.

Courault, D., Sequin B., and Olioso A.: Review on estimation of evapotranspiration from remote sensing data: From empirical to numerical modeling approaches, Irrig. Drain. Syst., 19, 223-249, 2005.

D’Urso, G. and Menenti, M.: Mapping crop coefficients in irrigated areas from Landsat TM images; Proceed, European Symposium on Satellite Remote Sensing II, Europto, Paris, sett.'95; SPIE, Intern. Soc. Optical Engineering, 2585, 41-47, 1995.

FAO: Crop evapotranspiration - Guidelines for computing crop water requirements, FAO Irrigation and Drainage Papers 56, Food and Agriculture Organization of the United Nations, 1998.

Fedra, K., Kubat, M., and Zuvela-Aloise, M.: Web-based water resources management: economic valuation and participatory multi-criteria optimization. Proceedings of the Second IASTED International Conference WATER RESOURCES MANAGEMENT 20-22 August 2007, Honolulu, Hawaii, USA ISBN Hardcopy: 98-0-88986-679-9 CD: 978-0-88986-680-5, 2007.

French, A. N., Schmugge, T. J., and Kustas, W. P.: Estimating evapotranspiration with ASTER thermal infrared imagery, Geoscience and Remote Sensing Symposium, 2, 718-720, 2001.

Gieske, A. and Wouter M.: High density NOAA time series of ET in the Gediz Basin, Turkey. Irrig. Drain. Syst., 19, 285-299, 2005.

Hadjimitsis, D. G., Clayton, C. R. I., and Retalis, A.: Darkest pixel atmospheric correction algorithm: a revised procedure for environmental applications of satellite remotely sensed imagery, In Proc. 10th International Symposium on Remote Sensing, Barcelona, Spain 5239, 464-471, 2004.

Hadjimitsis, D. G., Papadavid, G., and Kounoudes, A.: Integrated method for monitoring irrigation demand in agricultural fields in Cyprus using satellite remote sensing and wireless sensor network, In Proc. 4th International Conference on Information \& Communication Technologies in Bio \& Earth Sciences, 18-20 September 2008, Athens, Greece, 2008.
Hafeez, M. M., Chemin, Y., Van De Giesen, N., and Bouman, B. A. M.: Field Evapotranspiration Estimation in Central Luzon, Philippines, Using Different Sensors: Landsat 7 ETM+, Terra Modis and Aster, In Proc. Symposium on Geospatial Theory, Processing and Applications, Ottawa, 2002.

Harmancioglu, N. Fedra, K., and Barbaros, F.: Analysis of Sustainability in Management of Water Scarce Basins: the case of the Gediz River Basin in Turkey, Desalination, 226, 175-182, 2008.

Hoedjes, J. C. B., Chehbouni, A., Jacob, F., Ezzahar, J., and Boulet, G.: Deriving daily evapotranspiration from remotely sensed instantaneous evaporative fraction over olive orchard in semi-arid Morocco, J. Hydrol., 354, 53-64, 2008.

Hongjun L., Zheng L., Yuping L., Chunqiang L., Zhijun L., and Shengwei Z.: Estimation of water consumption and crop water productivity of winter wheat in North China Plain using remote sensing technology, Agr. Water Manag., 95, 1271-1278, 2008.

Klohn, W.: Reassessment of the island's water resources and demand. Synthesis Report, Ministry of Agriculture, Natural Resources and Environment of the Republic of Cyprus, WDD, and FAO, Land and Water development Division, FAO/WDD TCP/CYP/2801, 31 pp, 2002.

Liang S.: Narrowband to broadband conversions of land surface albedo: I Algorithms. Remote Sens. Environ., 78, 213-238, 2000.

Papadavid, G. C., Agapiou, A., Michaelides, S., and Hadjimitsis, D. G.: Brief communication "The integration of remote sensing and meteorological data for monitoring irrigation demand in Cyprus", Nat. Hazards Earth Syst. Sci., 9, 2009-2014, doi:10.5194/nhess-9-2009-2009, 2009.

Qin, Z. and Karnieli, A.: A mono-window algorithm for retrieving land surface temperature from Landsat TM data and its application to the Israel-Egypt border region, Int. J. Remote Sens., 22, 3719-3746, 2001.

Sobrino, J. A., Jiménez-Muñoz, J. C., and Paolini, L.: Land surface temperature retrieval from LANDSAT TM 5, Remote Sens. Environ., 90, 434-440, 2004.

Stathopoulou, M., Cartalis, C., and Petrakis, M.: Integrating Corine Land Cover data and Landsat TM for surface emissivity definition: application to the urban area of Athens, Greece, Int. J. Remote Sens., 28, 3291-3304, 2007.

Zoran, M. and Stefan, S.: Atmospheric and spectral corrections for estimating surface albedo from satellite data, J. Optoelectron. Adv. M., 8, 247-251, 2006. 